\title{
Computational Study of Stratified Combustion in an Optical Diesel Engine
}

\section{Mohammed Jaasim Mubarak ali, Francisco Hernandez Perez, R Vallinayagam, S Vedharaj, Bengt Johansson, and Hong Im}

King Abdullah University of Science \& Technology

CITATION: Mubarak ali, M., Hernandez Perez, F., Vallinayagam, R., Vedharaj, S. et al., "Computational Study of Stratified Combustion in an Optical Diesel Engine," SAE Technical Paper 2017-01-0573, 2017, doi:10.4271/2017-01-0573.

Copyright (C) 2017 SAE International

\begin{abstract}
Full cycle simulations of KAUST optical diesel engine were conducted in order to provide insights into the details of fuel spray, mixing, and combustion characteristics at different start of injection (SOI) conditions. Although optical diagnostics provide valuable information, the high fidelity simulations with matched parametric conditions improve fundamental understanding of relevant physical and chemical processes by accessing additional observables such as the local mixture distribution, intermediate species concentrations, and detailed chemical reaction rates. Commercial software, CONVERGETM, was used as the main simulation tool, with the Reynolds averaged Navier-Stokes (RANS) turbulence model and the multi-zone (SAGE) combustion model to compute the chemical reaction terms. SOI is varied from late compression ignition (CI) to early partially premixed combustion (PPC) conditions. The simulation results revealed a stronger correlation between fuel injection timing and combustion phasing for late SOI conditions, whereas the combustion phasing starts to decouple from SOI for early SOI cases. The predictions are consistent with the experimental observations, in terms of the overall trends in combustion and emission characteristics, while the high fidelity simulations provided further insights into the effects of mixture stratifications resulting from different SOI conditions.
\end{abstract}

\section{Keywords}

Optical diesel engine, engine simulations, stratification, injection timing, partially premixed combustion

\section{Introduction}

Diesel engines are widely used for light and heavy duty transportation applications, in favor of their higher thermal efficiency $[\underline{1}, \underline{2}]$. On the other hand, tradeoff between particulate $[\underline{3}, \underline{4}]$ and $\mathrm{NO}_{\mathrm{X}}$ emission is a major challenge [ $\underline{5}]$. Over the years, emission regulations have become stringent and the need to reduce emissions without compromising efficiency is essential. Since the design of diesel engines has evolved into a standardized form, development of new engine concepts with different thermodynamic cycles or new geometries is not feasible for commercial production in the immediate future. Therefore, researchers are investigating new combustion concepts within the existing hardware to simultaneously reduce $\mathrm{NO}_{\mathrm{X}}$ and soot emission and to improve engine performance $[\underline{6}, 7]$. In particular, different combustion modes can be explored, such as homogeneous charge compression ignition (HCCI), partially premixed combustion (PPC), and compression ignition (CI), by varying the fuel injection timings.

All advanced combustion strategies are based on controlling the local equivalence ratio and flame temperature, which have a significant effect on combustion and emission performances []]. While HCCI is a low temperature combustion (LTC) concept that reduces the flame temperature by enhancing premixing, precise control of ignition and combustion phasing is a significant challenge $[\underline{9}, \underline{10}]$. As an improvement, PPC has recently been investigated as a means to improve the combustion control by introducing stratification into nearly homogeneous combustion $[\underline{11}, \underline{12}]$. This is achieved by advancing the start of injection (SOI) to a proper level, increasing the exhaust gas recirculation (EGR) rate and increasing intake air temperature. SOI for PPC is in between those at CI and HCCI conditions, so that the mixture is partially premixed before combustion. To prevent premature auto-ignition at early SOI, fuels with high research octane number (RON) is considered as an enabler to achieve PPC in conventional CI engine, although PPC with diesel fuel has been realized by Toyota and Nissan by utilizing UNIBUS [13] and modulated kinetics (MK) [14] technique. 
Optical engine provide details about the combustion behavior of fuels, which can be utilized to understand turbulence, combustion and species formation inside the engine. In-cylinder optical diagnostics can also be used to investigate fuel spray atomization prior to combustion process in $\mathrm{CI}$ engine. Recently, optical diesel engines have been investigated for PPC applications $[\underline{10}, \underline{11}, \underline{12}, \underline{15}, \underline{16}, \underline{17}]$. Based on the natural luminosity of images or from $\mathrm{OH}$ chemiluminisence, in-cylinder combustion behavior for PPC is reported $[\underline{18}, \underline{19}, \underline{20}, \underline{21}]$.

A recent study reports that using primary reference fuels to explore PPC is beneficial because the reduced chemical kinetic mechanism with limited number of species and reactions facilitate computation modeling [22]. When using PRF55 in optical diesel engine, longer ignition delay and premixing ensured PPC and combustion control was achieved by dilution of intake air with EGR [21]. A recent study reported the separation of SOI from combustion phasing at early fuel injection conditions [21] , along with the finding that an increased level of stratified combustion at late SOI. While optical engine studies provide valuable information about PPC engine characteristics, the diagnostic techniques are limited to some specific observables. To this end, high fidelity simulations with matched engine geometry and boundary conditions can provide further insights by revealing detailed spatial and temporal behavior of quantities that cannot be measured experimentally.

The present study focuses on simulation of stratified combustion in an optical diesel engine using three dimensional CFD code, CONVERGETM . Physical properties of diesel were incorporated to the code and the gas phase chemical kinetics was represented using n-heptane comprehensive combustion chemistry. In the experimental study, PPC was achieved by advancing the fuel injection timing from late to early injections and a clear distinction between different combustion regimes were identified at a low load and an engine speed of $1200 \mathrm{rpm}$. These cases $\left(\mathrm{T}_{\text {in }}=35^{\circ} \mathrm{C}\right.$ and $\left.\mathrm{O}_{2}=20.7 \%\right)$ were simulated for diesel at various SOI conditions and compared with experimental results.

It will be shown by the simulation study that below a certain SOI level the combustion phasing is separated from SOI, consistent with the experimental findings that CA50 reaches a minimum value as $\mathrm{SOI}$ was advanced. The in-cylinder pressure, rate of heat release, NOx and soot emissions were compared with the experimental data. Temperature, equivalence ratio and $\mathrm{OH}$ mass fraction contours obtained from simulation provide more insights and explains PPC condition in detail. The numerical results were investigated in detail in order to substantiate the experimental results and provide improved understanding.

\section{Experimental Set Up}

AVL single cylinder optical diesel engine with chamber volume of $551 \mathrm{cc}$ was used for the experimental study. The schematic of the optical diesel engine with camera and other accessories used in the experiments is shown in Figure 1(a). The piston bowl made up of quartz provides the optical access inside the cylinder and high speed video is captured through a mirror from the bottom of piston. A high speed video of combustion process is recorded using photron

FASTCAM SA4 color camera. The video is captured at 10,000 frames per second with pixel resolution of $768 \times 512$ and aperture for lens is 1.4. The start of injection, injection pressure and valve timing are controlled by engine control unit (ECU) known as AVL FI2RE. A piezoelectric pressure transducer mounted on cylinder head is used to measure the cylinder pressure with a sensitivity of $20 \mathrm{pC} / \mathrm{bar}$. The recorded in-cylinder pressure data was later used to derive rate of heat release and CA50.

\section{Computational Methodology}

Numerical simulations were performed using three-dimensional computational fluid dynamics (CFD) code, CONVERGETM, which has been commonly used for engine applications. Finite volume method was used to discretize the conservation equations in the physical space [23] . The CAD geometry generated for the current study is shown in Figure 1(b) and the mesh generated in-situ is shown in Figure 1(c). The initial base grid is generated with a size of $4 \mathrm{~mm}$ in all three directions. Adaptive mesh refinement (AMR) technique was used to refine the grid locally based on the absolute value of temperature gradient $(5 \mathrm{~K})$ between the neighboring cells. The AMR of level 5 (minimum cell size $\left.=\mathrm{dx} / 2^{\text {(level) }}\right)$ refines the cells to a minimum size of $0.125 \mathrm{~mm}$. A grid-independent solution is obtained for $0.125 \mathrm{~mm}$ grid size.

A fixed embedding of level 5 was used during the spray injection to capture the spray events with higher resolution. The flow inside the nozzle is not considered in this simulation. The experimental motored cycle was simulated to match the compression ratio to account for the blow by and obtain the initial and boundary conditions for the fired simulations. Simulation was performed by utilizing spray, turbulence, combustion and heat loss model to obtain a detailed understanding of the combustion and emission behavior of CI engine operated on diesel fuel. The spray breakup is represented by Kelvin Helmholtz/ Rayleigh Taylor (KH-RT) model [24, 25] that breaks up liquid core to larger droplets and then into smaller droplets. Evaporation of the droplets is governed through mass conservation equations, also it is assumed that the droplets always posses spherical shape and uniform temperature throughout the droplet. Recirculation inside the droplets is accounted by Abramzon model [26]. Effective liquid-air diffusivity is calculated utilizing Newton-Raphson method. A square injection rate shape profile was assumed for all simulation cases.

Reynolds averaged Navier-Stokes (RANS) turbulence is used to describe in-cylinder turbulent flow field. Turbulence inside the cylinder is represented using the renormalized group k-epsilon model developed by Han and coworkers [27]. Heat loss model by Reitz and coworkers [28] was used to account for the heat loss through the cylinder walls. Gas phase chemical kinetics is solved with multi-zone SAGE model [29], which groups the cells into zones based on equivalence ratio and temperature bins of 0.05 and $5 \mathrm{~K}$. More details about the models used can be found in CONVERGE manual [무] ]. 


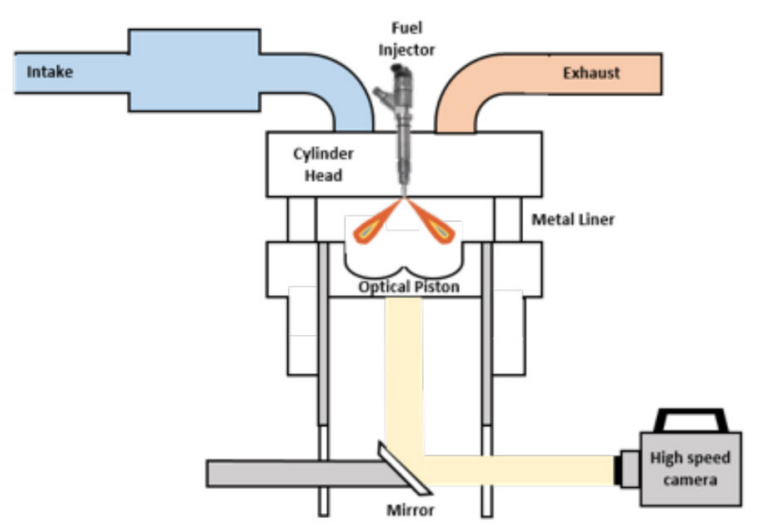

(a)

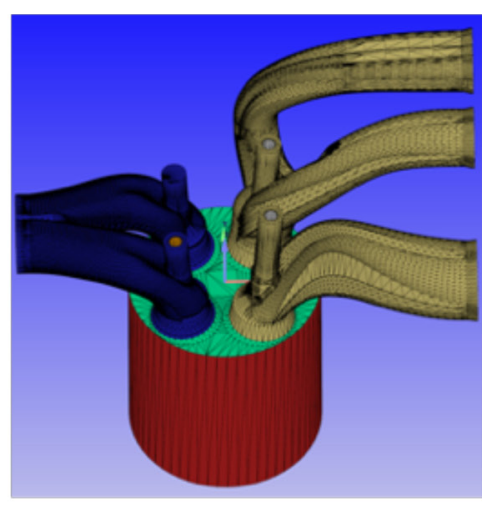

(b)

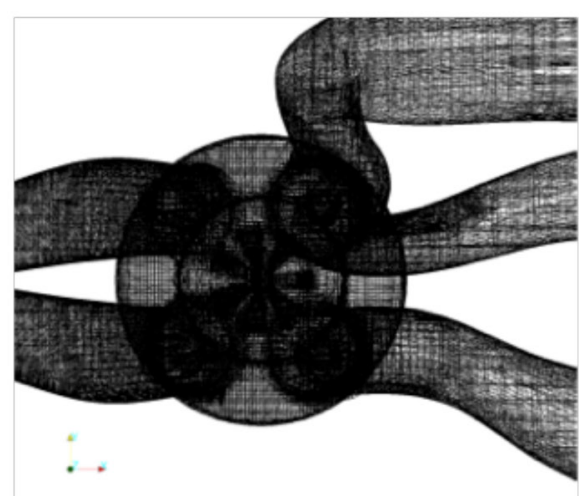

(c)

Figure 1. (a) Schematic of optical diesel engine, (b) Three-dimensional model of the KASUT optical CI engine, (c) Geometric mesh of the computational domain

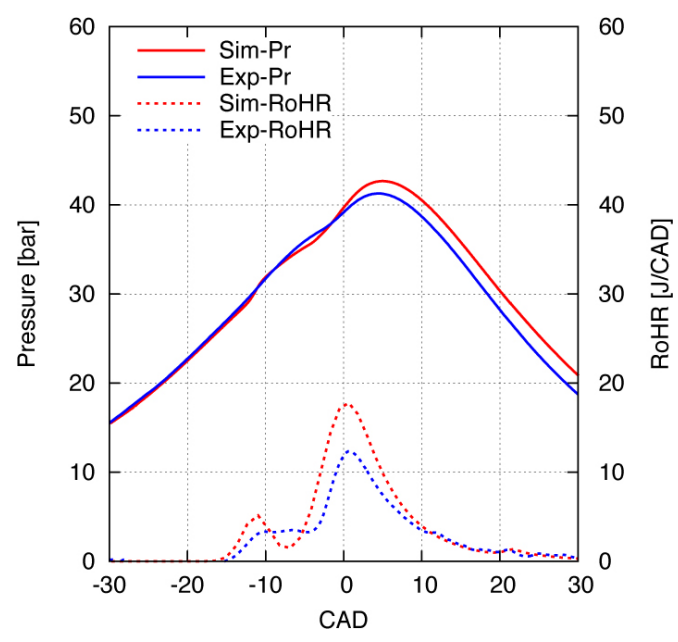

a. SOI -30 CAD

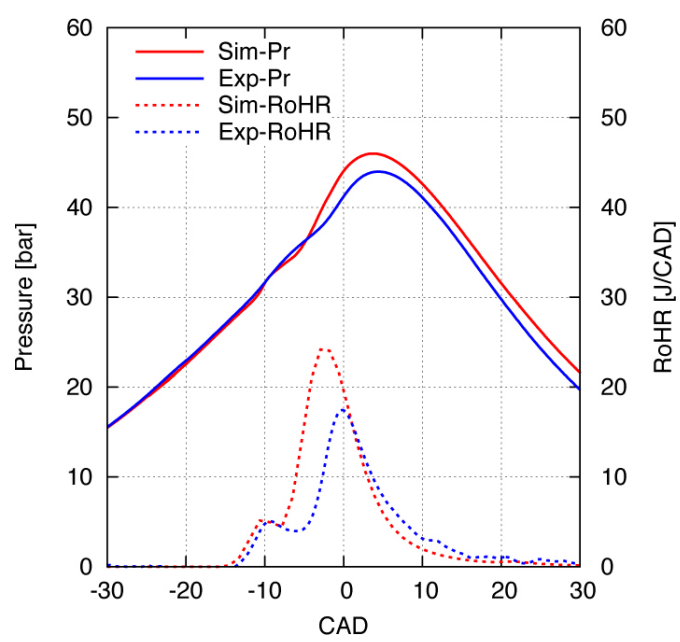

b. SOI -25 CAD

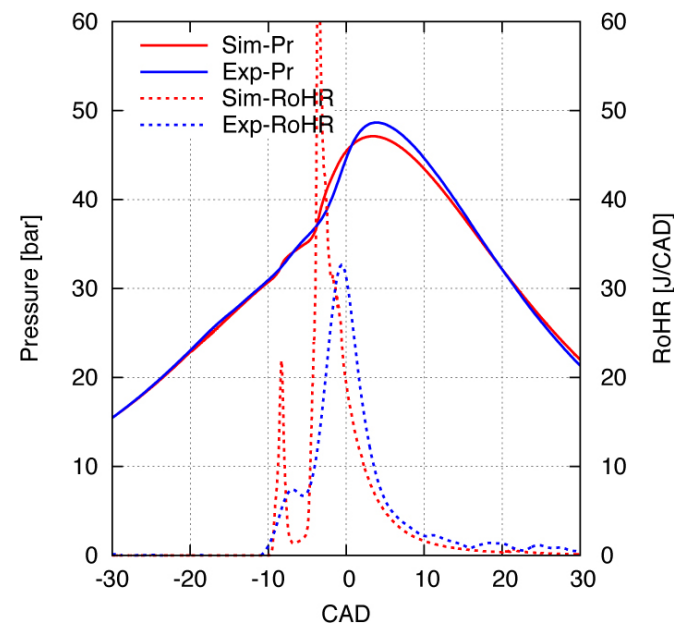

c. SOI $-20 \mathrm{CAD}$

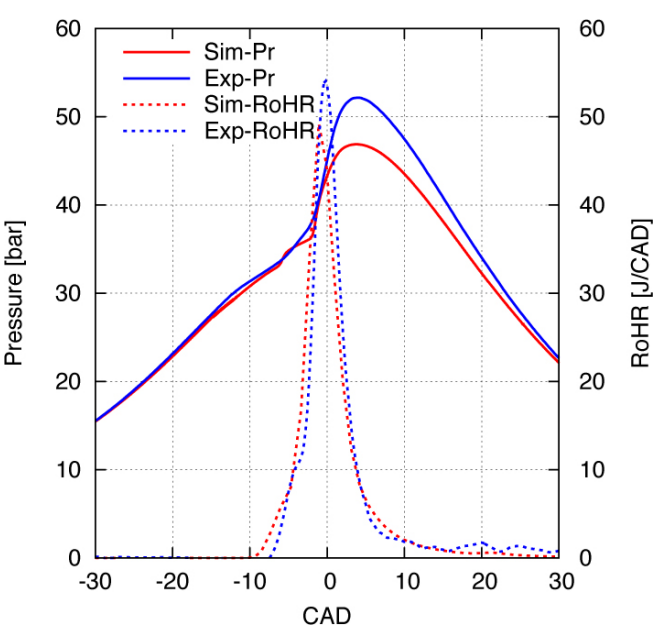

d. SOI -15 CAD

Figure 2. (cont.) Comparison of in-cylinder pressure and rate of heat release from engine experiment and simulation at various SOI.

Figure 2. 

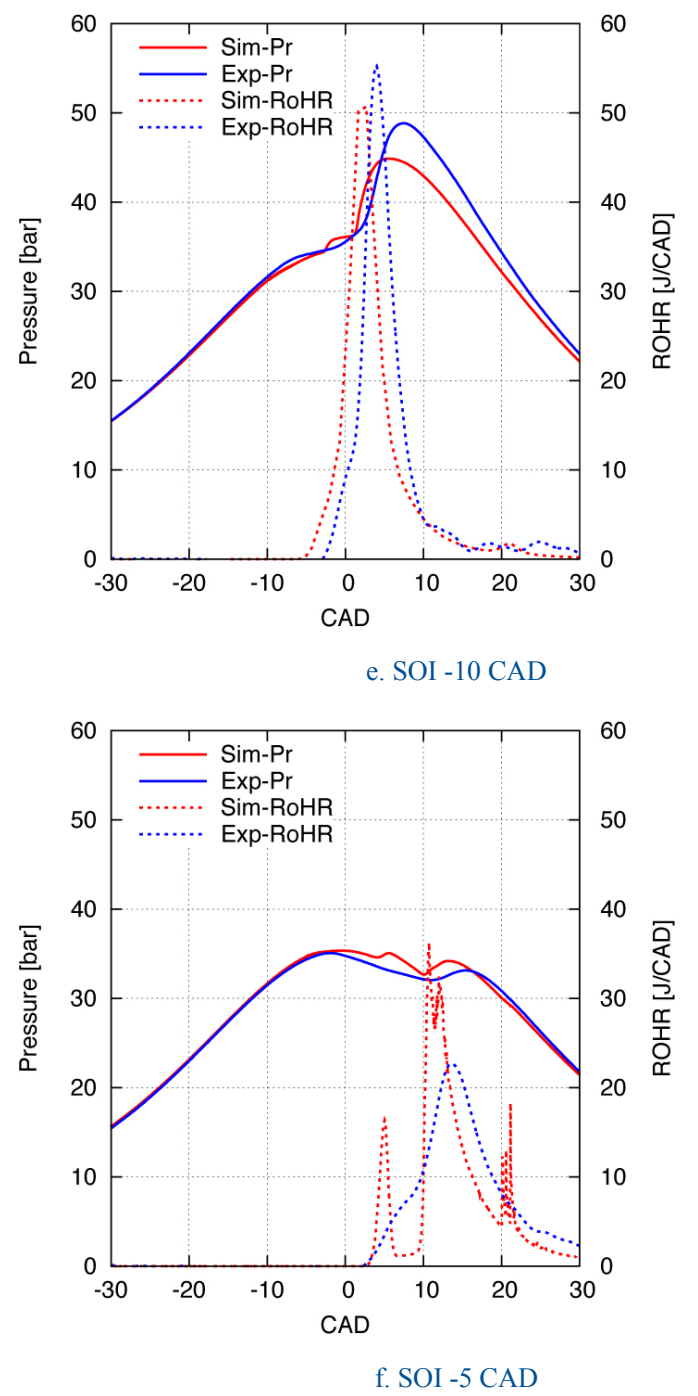

Figure 2. (cont.) Comparison of in-cylinder pressure and rate of heat release from engine experiment and simulation at various SOI.

\section{Experimental and Numerical Simulation Conditions}

Experiments were performed in AVL optical diesel engine and the detailed specifications are shown in Table 1. It is a single cylinder engine that has an optical piston and high speed images are captured from the bottom using a mirror. The engine operates at a speed of $1200 \mathrm{rpm}$ and pressure at TDC is kept at 35 bar. The intake air temperature is maintained at $35^{\circ} \mathrm{C}$ and $6 \mathrm{mg}$ of fuel is injected to produce IMEP at around 3 bar (low load condition). While SOI is swept from late to early fuel injection timing, the fuel injection pressure was maintained at 800 bar. The engine operating conditions were provided as input parameters to numerical simulation (Table 1). Simulation was performed to understand mixing, combustion and emission behavior of diesel fuel at different SOI. Physical properties of diesel fuel were incorporated to the code and the gas phase kinetics was represented using n-heptane chemical kinetic mechanism developed by Valeri et al. [31] with 40 species and 165 reactions.
Table 1. Engine specifications and operating conditions for experiments and simulations

\begin{tabular}{|l|l|}
\hline Bore & $85 \mathrm{~mm}$ \\
\hline Stroke & $90 \mathrm{~mm}$ \\
\hline Connecting rod length & $138 \mathrm{~mm}$ \\
\hline No of valves & 4 (2-intake, 2-exhaust) \\
\hline Piston shape & Mexican hat (optical) \\
\hline Compression ratio & 9.5 \\
\hline Intake temperature & $308 \mathrm{~K}$ \\
\hline Intake pressure & $1.45 \mathrm{bar}$ \\
\hline Engine speed & $1200 \mathrm{rpm}$ \\
\hline Fuel & US NO.2 Diesel \\
\hline Start of injection & $-30,-25,-20,-15,-10,-5$ CAD aTDC \\
\hline Amount of fuel injected & $6 \mathrm{mg} / \mathrm{cycle}$ \\
\hline Injection pressure & $800 \mathrm{bar}$ \\
\hline Piston temperature & $400 \mathrm{~K}$ \\
\hline Head temperature & $400 \mathrm{~K}$ \\
\hline Liner temperature & $380 \mathrm{~K}$ \\
\hline
\end{tabular}

\section{Results and Discussion}

Figure 2 shows the comparison of the experimental and simulated in-cylinder pressure trace and the rate of heat release. Good qualitative and quantitative agreement is found for a range of SOI conditions. The simulated rate of heat release slightly over predicts the experimental results and SOC is comparable between experimental and numerical results. The level of agreement justifies the use of the simulation results to understand the corresponding experimental data. Note that there is small peak in heat release before the main premixed heat release at early SOI. At late injection conditions (-10 CAD aTDC and -5 CAD aTDC), however, such a secondary peak is not evident and a conventional stratified CI combustion behavior is observed. This difference is attributed to the fact that the diesel exhibits low temperature combustion characteristics at early SOI. In particular, when SOI is advanced more than -20 CAD (aTDC), the first stage heat release peak is observed as a result of low temperature chemistry. The numerical simulation successfully captured this phenomenon, confirming the validity of the chemical kinetic mechanism used in the model.

To further examine this behavior, the high-speed images of the combustion process from the experiments and simulations at early and late injections are shown in Figure 3. It is seen that as SOI is advanced, premixing is increased and this is the evidence of low temperature combustion pointed out from the numerical study herein. This is also in consistent with the high speed combustion images captured experimentally, wherein mixture becomes uniform as SOI is advanced. The decreased luminosity of images is an indication of increased premixing and turns out to be partially premixed combustion (PPC). In case of late injection timings, a clearly defined combustion cloud is discernable and the color of the images changes from blue to yellow. This stratified combustion regime represents typical CI condition in a diesel engine. The simulations qualitatively show the similar trend observed in the experiments for both early and late injection cases. 
CAD (aTDC)

\subsection{2}

\begin{abstract}
10.88
\end{abstract}
15.2

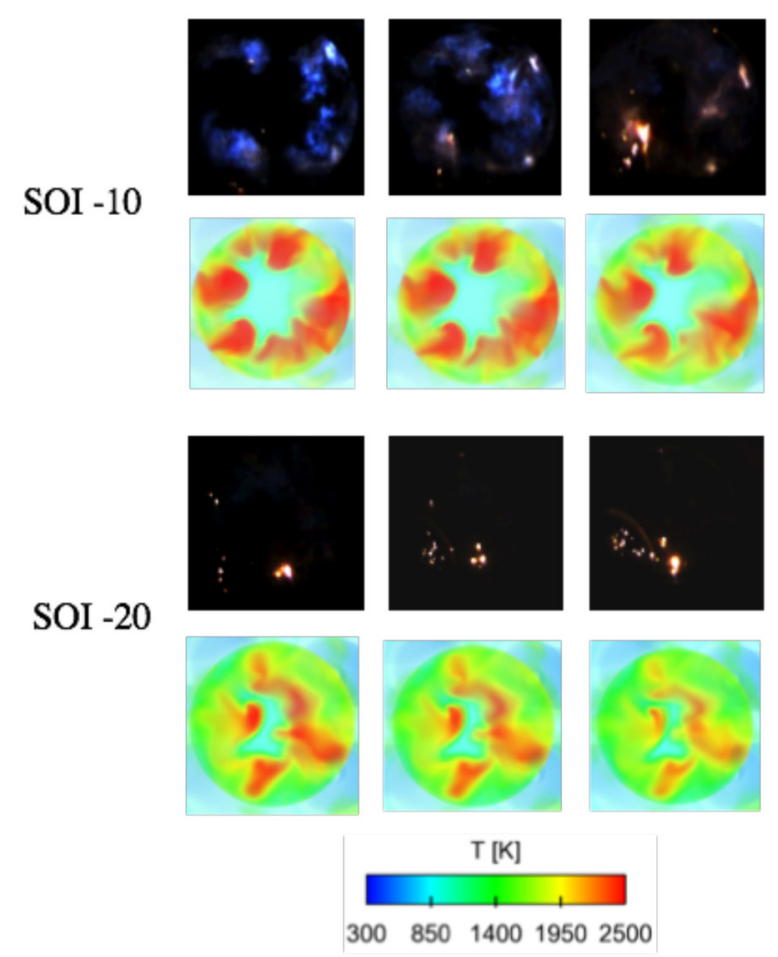

Figure 3. Comparison of high speed camera images and simulation results (Temperature contour).

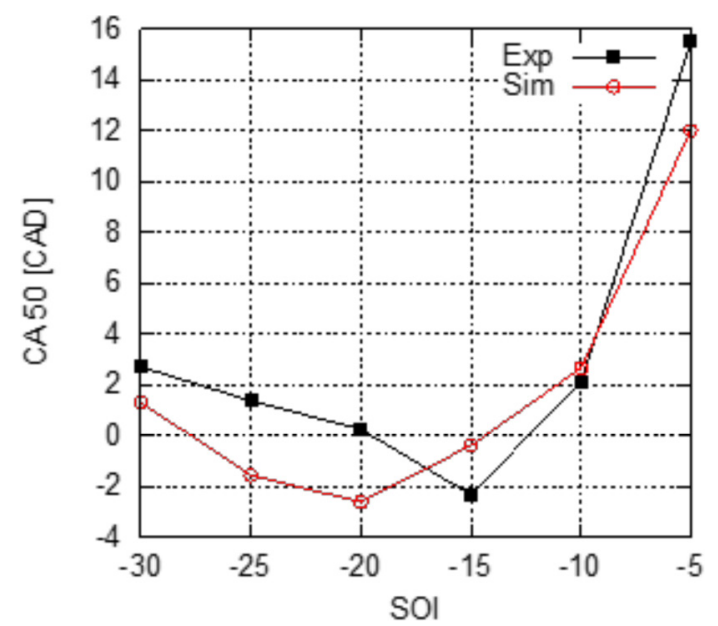

Figure 4. Comparison of combustion phasing (CA50) from experiments and simulations.
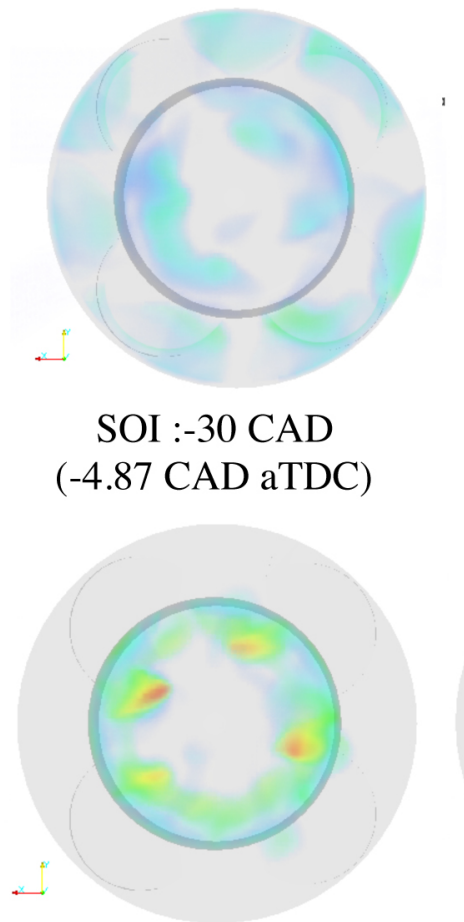

SOI: -15 CAD $(-2.06 \mathrm{CAD}$ aTDC)
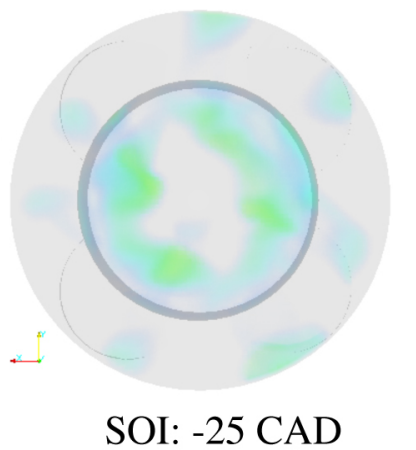
$(-6.28$ CAD aTDC)
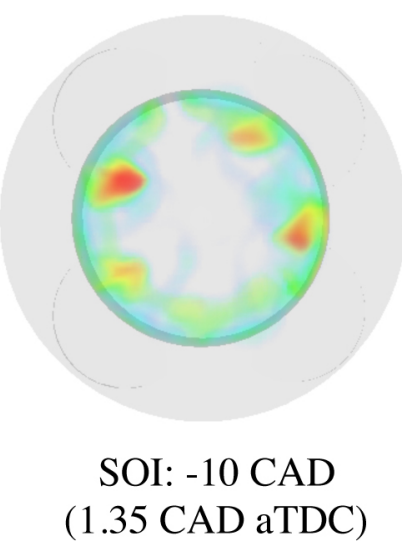

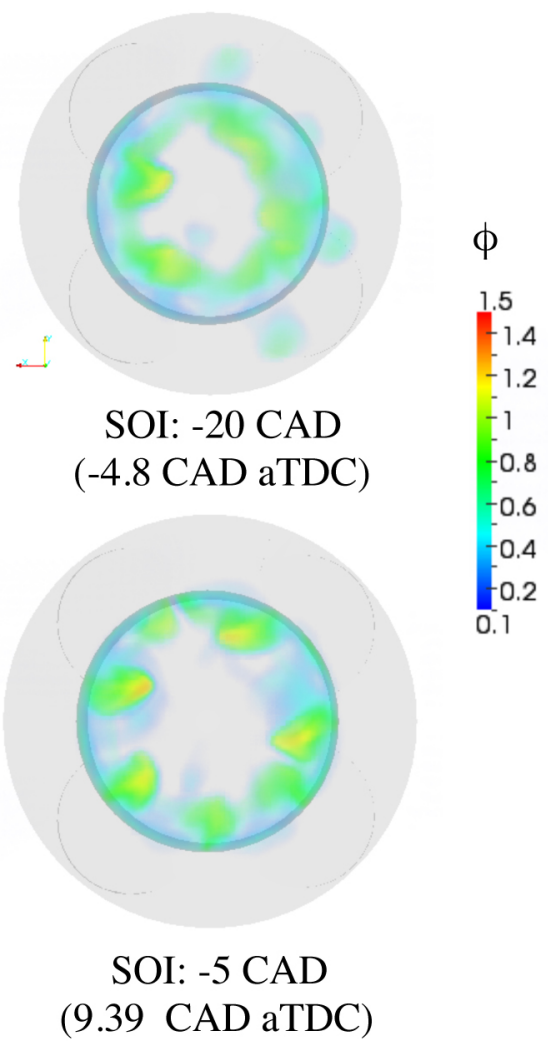

(9.39 CAD aTDC)

Figure 5. Volume rendered contour for equivalence ratio distribution at SOC 


\section{Combustion Phasing}

The combustion phasing is analyzed mainly in terms of CA50, defined as the crank angle at which $50 \%$ of heat is released. Figure 4 shows CA50 as a function of SOI, for both simulation and experimental results. The numerical prediction captures the behavior observed in the engine experiments, in that there exists a minimum CA50 as the $\mathrm{SOI}$ is varied from -30 to -5 CAD aTDC. While none of the SOI cases under considerations approaches HCCI limit, there appears to be an "optimal" SOI at which richer mixture pockets are formed at SOC. At earlier SOIs, the early spray, evaporation and mixing dilutes the mixture pockets prior to the start of combustion. For later SOIs, the spray does not have sufficient time to evaporate to create rich mixture pocket. It is observed that CA50 decreases from CI condition (-10 CAD aTDC) and then reverses at PPC condition (20 CAD aTDC). Thus, during late injections (CI condition), there is a link between combustion phasing and SOI; however, combustion phasing begins to decouple with SOI during early injections (PPC condition).

\section{Equivalence Ratio Distribution}

To further substantiate CA50 behavior, the equivalence ratio $(\varphi)$ distribution inside the cylinder was analyzed. Figure 5 show the volume-rendered equivalence ratio iso-contours at the start of combustion (SOC) for each condition. SOC was defined as the crank angle at which $\mathrm{OH}$ formation is initiated. The corresponding $\mathrm{CAD}$ at SOC is shown in Figure 5. While SOI of-30 CAD aTDC case shows highly non-uniform mixture field at SOC, implying that it is still far from HCCI condition, the later SOI cases (e.g. -10 and -15 CAD aTDC) clearly exhibit pronounced richer mixture pockets at SOC. In other words, comparing SOI of-30 and -15 CAD aTDC cases, while the overall large scale mixture fields are similar (created by the spray patterns), most of the richer mixture pockets are vanished for SOI of -30 CAD case by SOC, resulting in a slower start of combustion.

Figure 6 shows the probability density function (pdf) with respect to equivalence ratio, in order to provide a clear understanding of the nature of the mixture distribution. For all SOI, the pdf distribution can hardly be called that of a uniform mixture. However, the key difference is the amount of richer mixture pockets, shown in the inset of Figure 6, where non-monotonic behavior of rich mixtures is clearly seen as $\mathrm{SOI}$ varies from -30 to $-5 \mathrm{CAD}$, peaking at $-15 \mathrm{CAD}$.

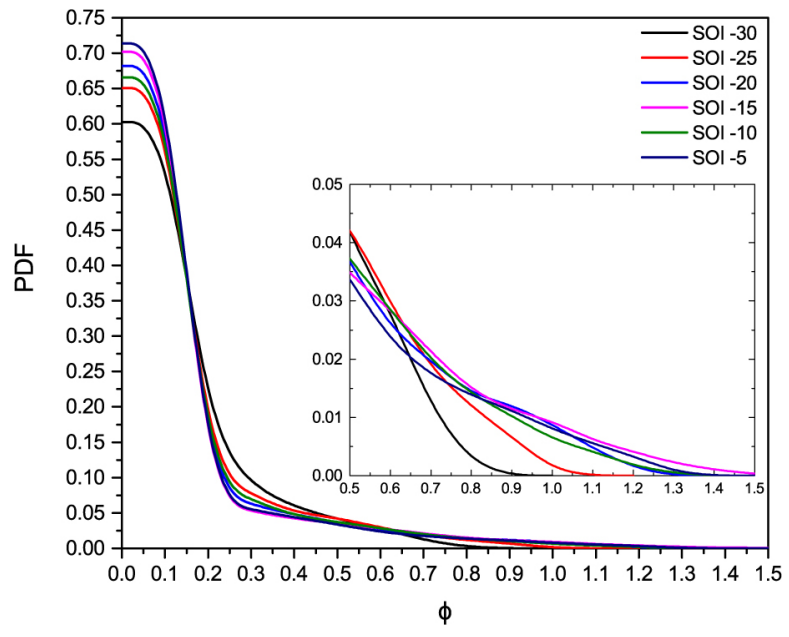

Figure 6. Volume weighted equivalence ratio PDF for various SOI's at start of combustion (SOC)

\section{Local Temperature Distribution}

Next, the local temperature distribution is investigated to identify the combustion characteristics variation in response to SOI. Figure 7 shows the comparison of temperature, equivalence ratio, and $\mathrm{OH}$ mass fraction iso-contours at CA50 for different SOI conditions. For early SOI of -30 CAD aTDC, the equivalence ratio field shows much more uniform mixture. Due to early injection, the fuel enters the squish region such that combustion and heat release events are widely distributed, as indicated by the temperature and $\mathrm{OH}$ iso-contours. For SOI of -25 and -20 CAD aTDC, the local temperature of the auto-ignited mixture is higher and combustion is initiated at the bowl, although some amount of fuel enters the squish region and burns at later times after SOC. For SOI at -15 CAD aTDC and later, fuel is completely contained inside the bowl. Again, local rich fuel pockets trigger ignition and the resulting temperature is higher, as seen from Figure 7. Examination of a single spray plume also revealed that no flame-liftoff was observed, which is a typical characteristic of diesel combustion at late injections. Figure 8 shows vertical cross-sections of the cylinder at CA50 for various SOI conditions. While it was not clear from Figure 6, it is now evident that combustion and heat release zones are the largest at SOI of -20 CAD aTDC, which explains why CA50 occurs at the earliest CAD for this case. At later SOI conditions, the combustion pockets are intense but their size becomes smaller, indicating that the late injection produced only a limited amount of fuel vapor ready for combustion.

\section{Ignition Location for Various Modes of Combustion}

Figure 9 shows the scatter plots of temperature and equivalence ratio, colored by $\mathrm{OH}$ mass fraction at $\mathrm{SOC}$, in order to investigate the mixture conditions at ignition. It is clearly seen that the mixture equivalent ratio at ignition becomes higher for a later SOI. Moreover, a larger amount of points with higher level of $\mathrm{OH}$ is seen for $\mathrm{SOI}$ at $-20 \mathrm{CAD}$ aTDC, implying that this condition provides the most reactive mixture $(0.9<\varphi<1.2)$ at SOC, thus resulting in early SOC.

\section{Emission Characteristics}

Zeldovich NOx model and Hiroyasu soot model [32] was used to calculate the emissions from the simulations quantitatively. Figure 10 shows the comparison of total NOx and soot emissions with experimental results as a function of SOI. The emission predictions from simulations were able to reproduce the experimental trends reasonably. The values of soot are very low from simulations, so an alternative analysis was conducted as discussed later.

Figure 11 shows T- $\varphi$ diagram indicating the most probable ranges of soot and NOx formation [ $\underline{33}]$, in which the scatter plot was overlaid indicating that all SOI cases have tendency to produce more NOx, since they operate at the equivalence ratio range below 2 . The scatter plot is colored with $\mathrm{OH}$ to indicate the location of combustion in $\mathrm{T}-\varphi$ space, implying that NOx production is active in that condition. Among the different cases, SOI of -15 CAD case produced maximum NOx due to combustion at high temperatures near TDC. 
SOI: -30 CAD

(1.32 CAD aTDC)

SOI: -25 CAD

$(-1.54$ CAD aTDC)
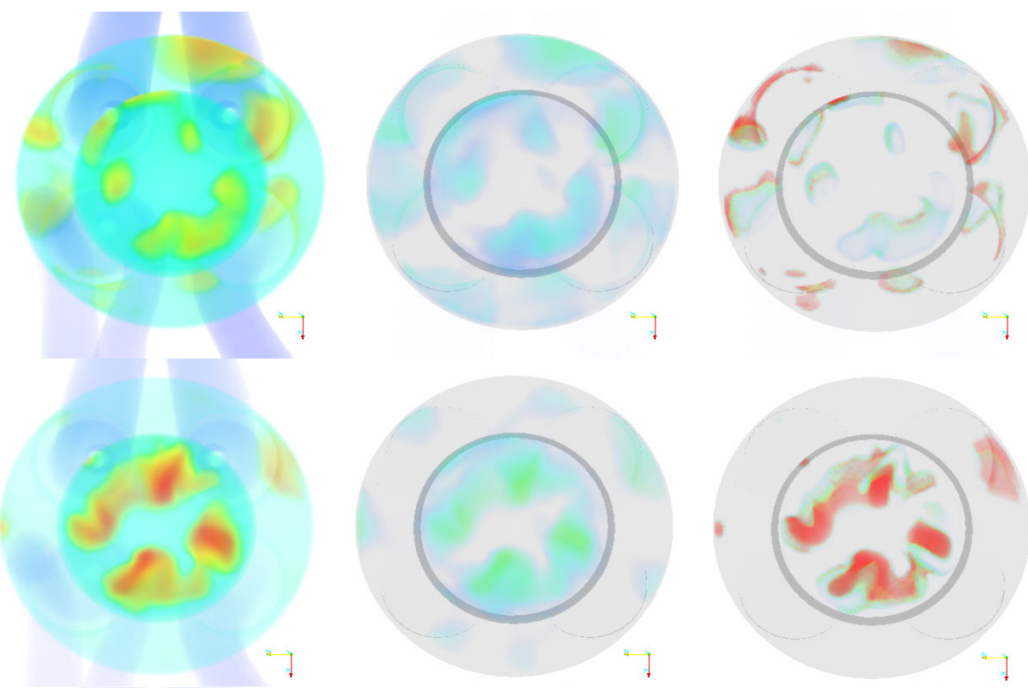

\author{
SOI: -20 CAD \\ $(-2.6 \mathrm{CAD}$ aTDC $)$ \\ SOI: -15 CAD \\ $(-0.36$ CAD aTDC) \\ SOI: -10 CAD \\ (-2.66 CAD aTDC) \\ SOI: -5 CAD \\ (12.01 CAD aTDC)
}
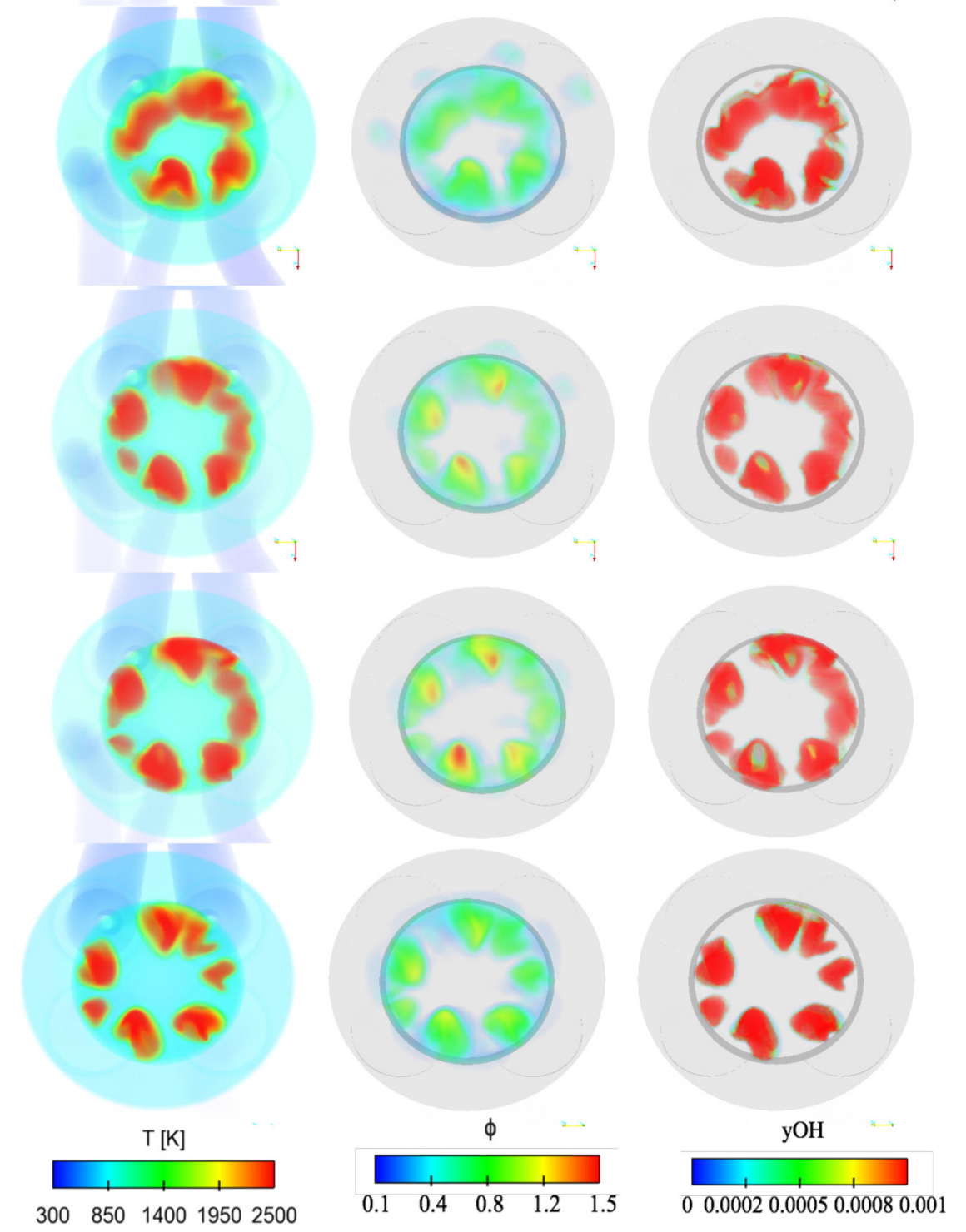

Figure 7. Volume contours of temperature, equivalence ratio and $\mathrm{OH}$ mass fraction for various $\mathrm{SOI}$ at CA50. 


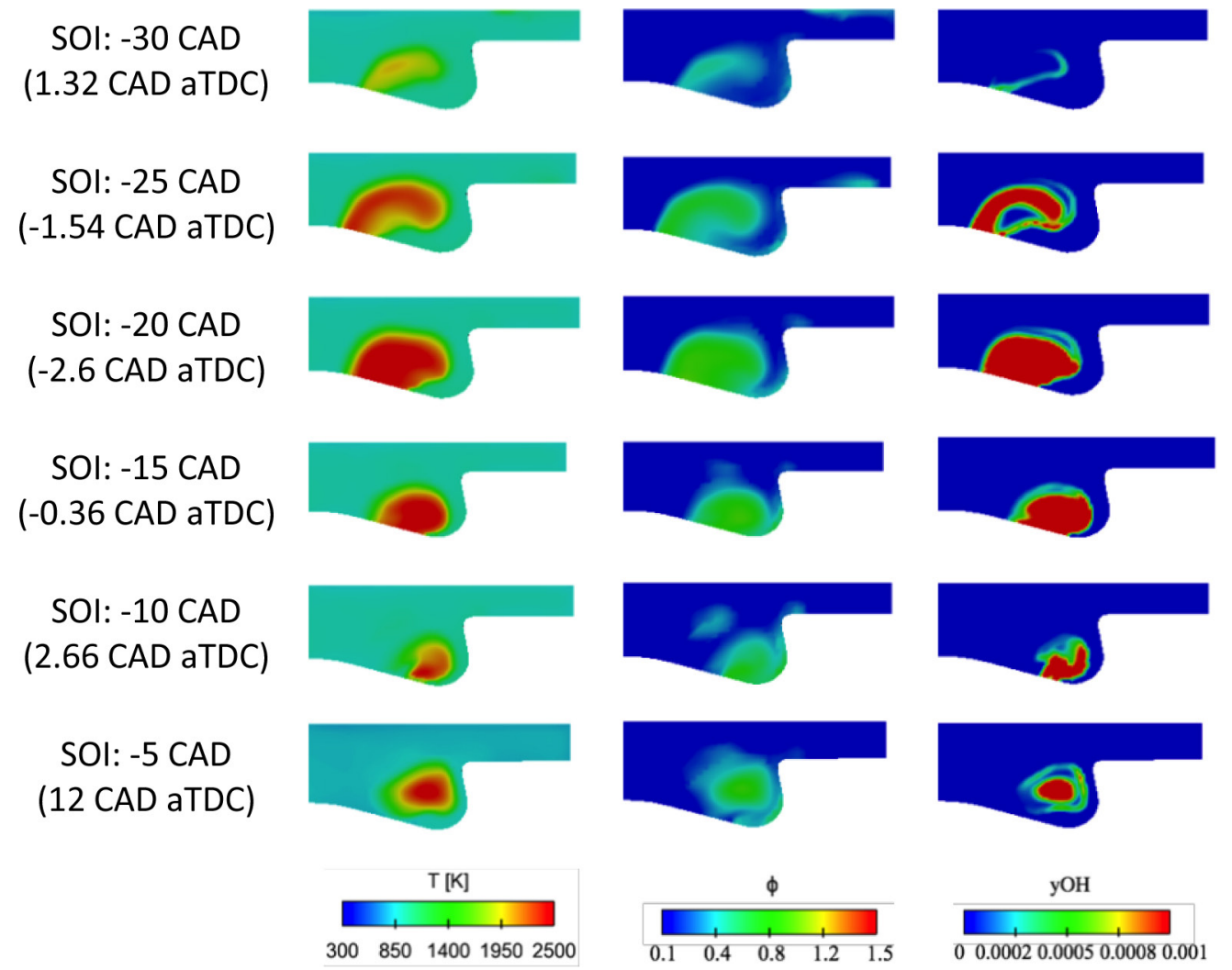

Figure 8. Y-Slice at CA 50 for temperature, equivalence ratio and $\mathrm{OH}$ mass fraction in-cylinder distribution for various SOI's

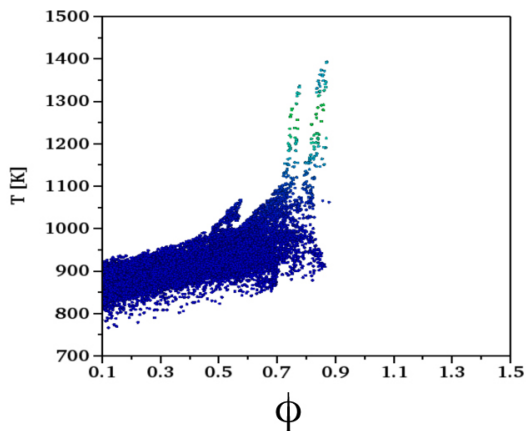

SOI: -30 CAD

$(-4.87$ CAD aTDC

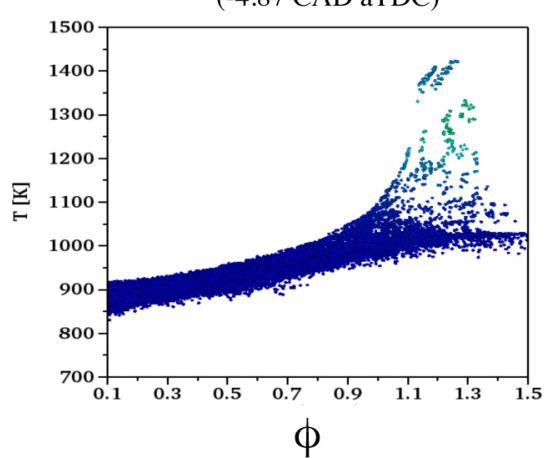

SOI: -15 CAD

$(-2.06$ CAD aTDC $)$

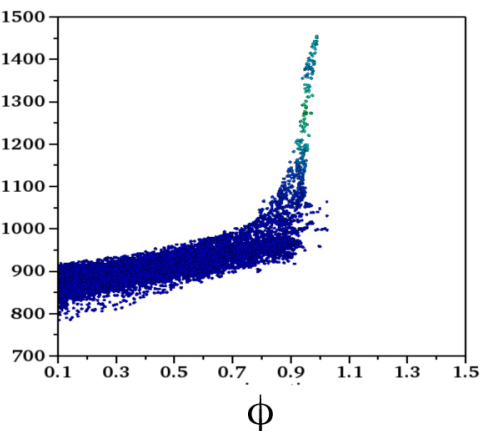

SOI: -25 CAD

$(-6.82$ CAD aTDC)

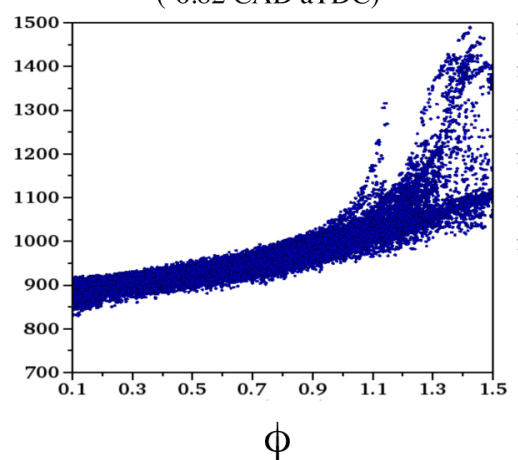

SOI: -10 CAD

$(-1.35 \mathrm{CAD}$ aTDC $)$

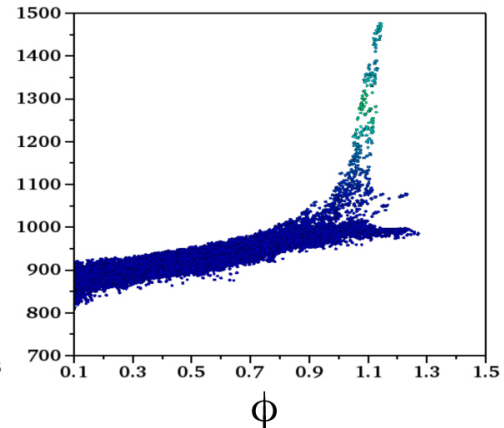

SOI: -20 CAD

$(-4.8$ CAD aTDC)

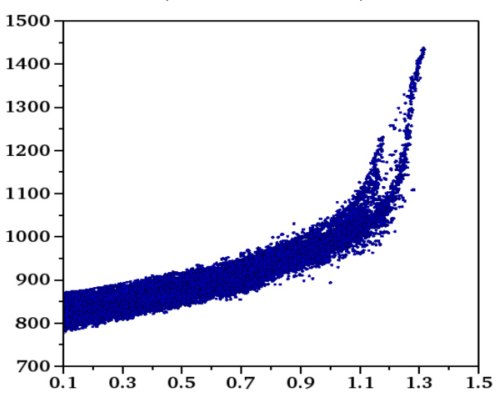

$\phi$

SOI: -5 CAD

(9.39 CAD aTDC)

Figure 9. Ignition location of T- $\varphi$ reactive space for various SOI's at SOC. 


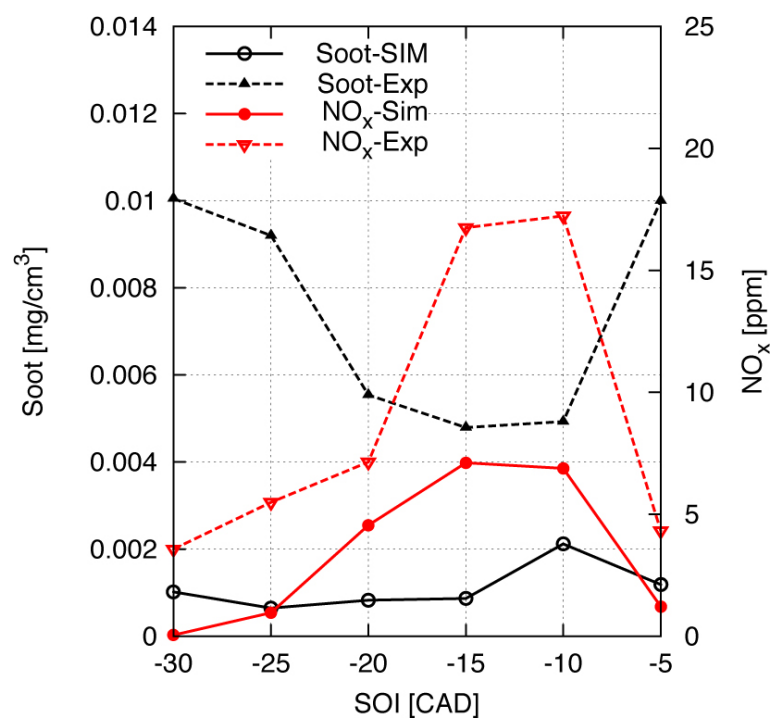

Figure 10. Total soot and NOx production during entire combustion duration

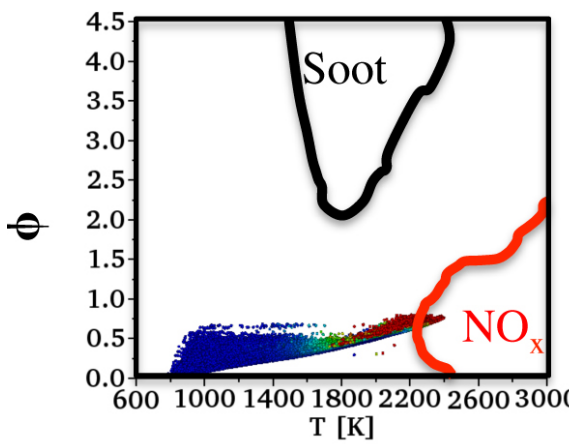

SOI: -30 CAD

(1.32 CAD aTDC)

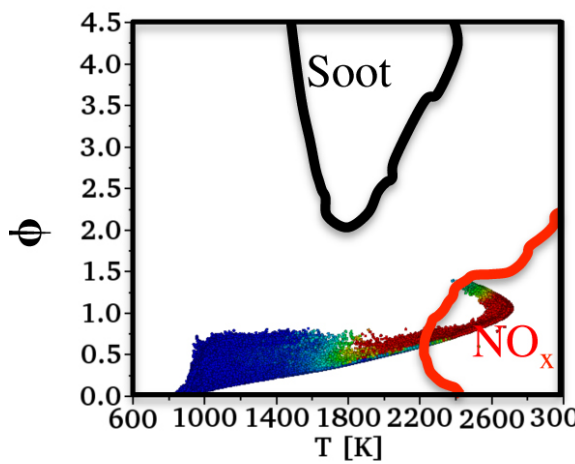

SOI: -15 CAD

$(-0.36$ CAD aTDC)

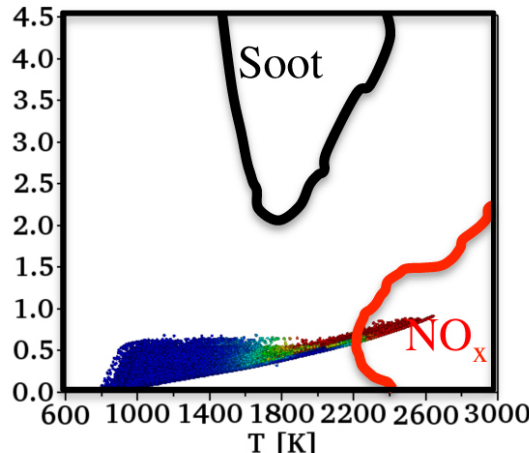

$\mathrm{T}[\mathrm{K}]$

SOI: -25 CAD

$(-1.54$ CAD aTDC)

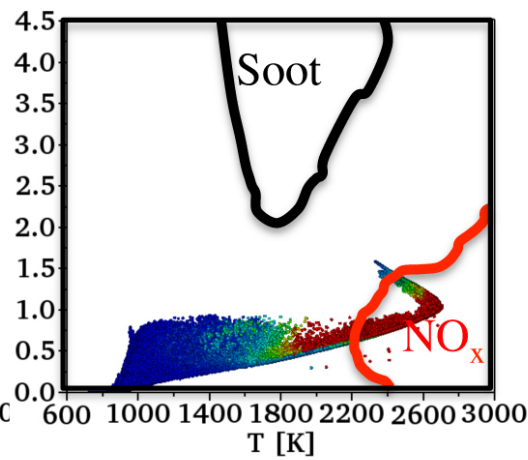

SOI: $-10 \mathrm{CAD}$

(2.66 CAD aTDC)

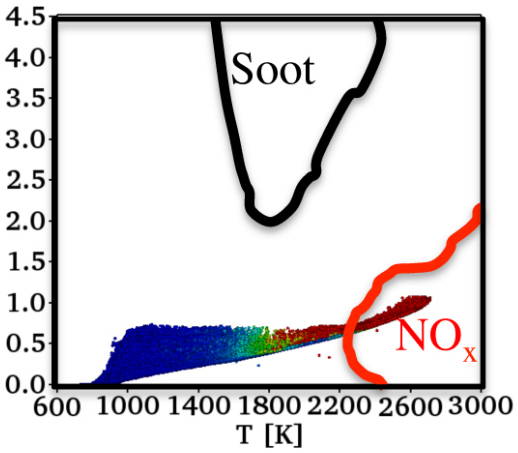

SOI: -20 CAD (-2.6 CAD aTDC)

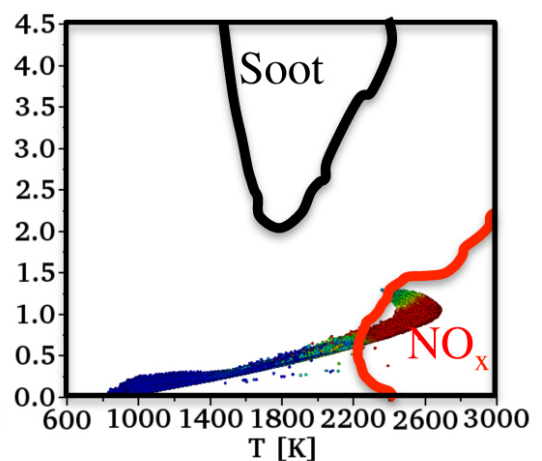

SOI: -5 CAD

(12.01 CAD aTDC)

Figure 11. T- $\varphi$ reaction space overlaid with soot-NOx regime at CA 50 for various SOI's 
CA10

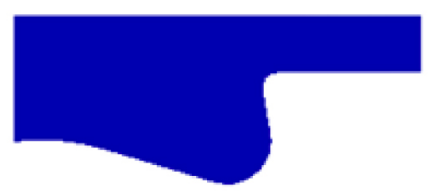

-9.6 CAD aTDC

SOI: -25 CAD

SOI: -20 CAD

SOI: -15 CAD

SOI: -10 CAD

SOI: -5 CAD

-6.42 CAD aTDC

-2.73 CAD aTDC

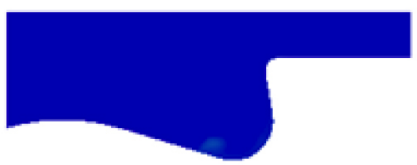

1.09 CAD aTDC

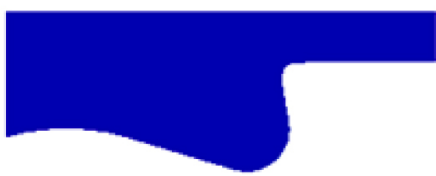

CA50

CA90

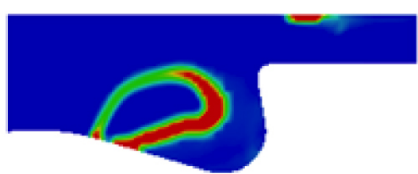

1.32 CAD aTDC

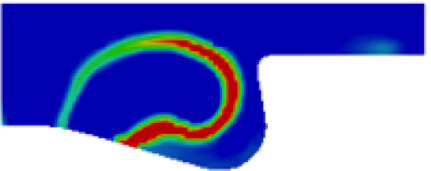

-1.54 CAD aTDC

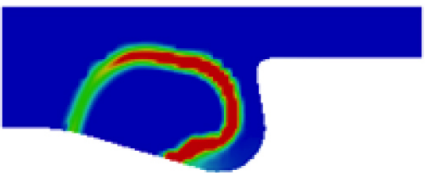

-2.6 CAD aTDC

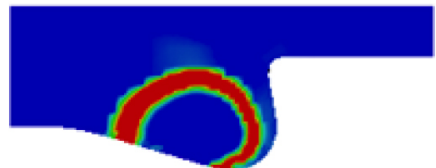

-0.36 CAD aTDC

5.8 CAD aTDC

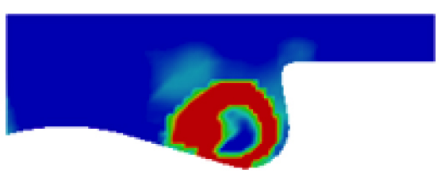

2.66 CAD aTDC

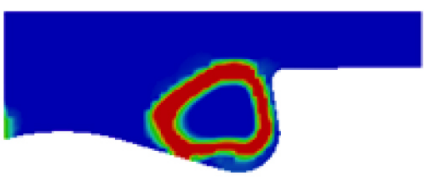

12.01 CAD aTDC

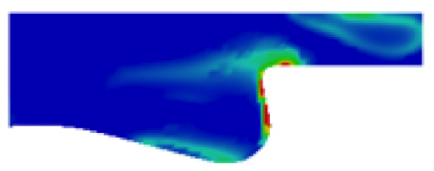

11.4 CAD aTDC

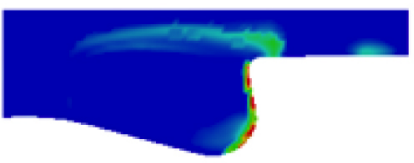

6.09 CAD aTDC

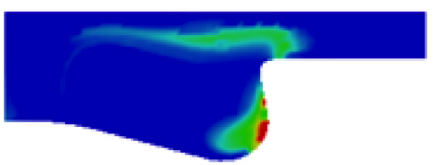

4.9 CAD aTDC

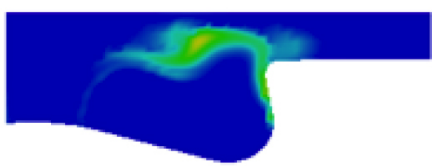

5.7 CAD aTDC

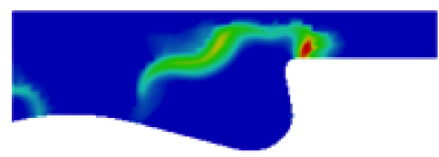

9.4 CAD aTDC

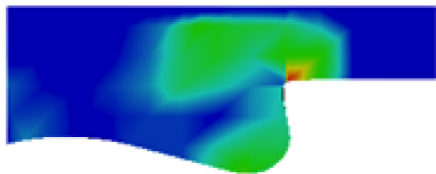

21.59 CAD aTDC $\mathrm{yC}_{2} \mathrm{H}_{2}$

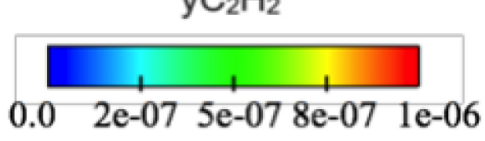

Figure 12. Y-Slice showing the in-cylinder $\mathrm{C}_{2} \mathrm{H}_{2}$ formation at CA 10, CA 50 and CA 90 for various SOI's. 
CA10

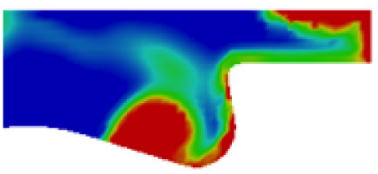

-9.6 CAD aTDC

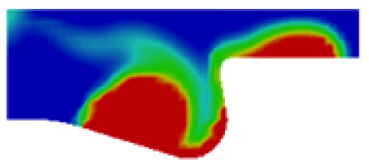

-6.42 CAD aTDC

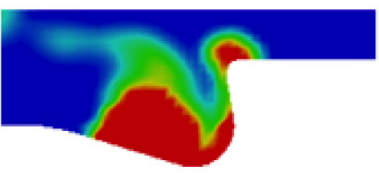

-4.73 CAD aTDC

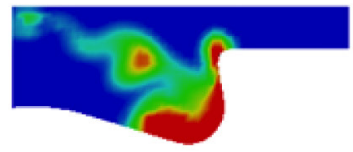

-2.73 CAD aTDC

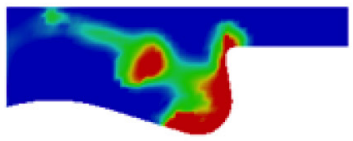

1.09 CAD aTDC

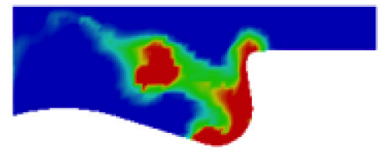

SOI: -5 CAD
CA50

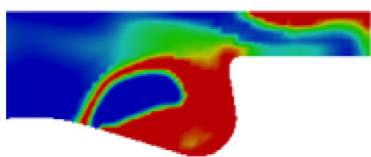

1.32 CAD aTDC

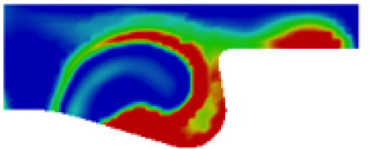

-1.54 CAD aTDC

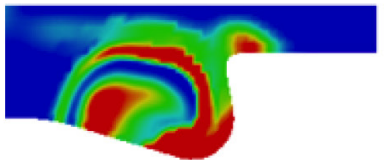

-2.6 CAD aTDC

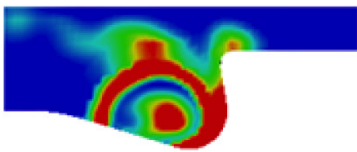

-0.36 CAD aTDC

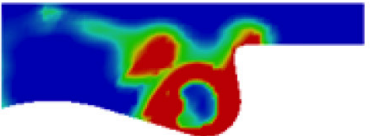

2.66 CAD aTDC

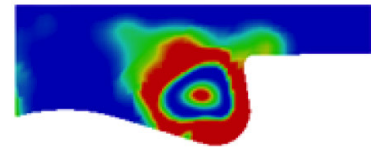

12.01 CAD aTDC $\mathrm{yCO}$

$\begin{array}{lllll}0.0 & 0.001 & 0.0025 & 0.004 & 0.005\end{array}$
CA90

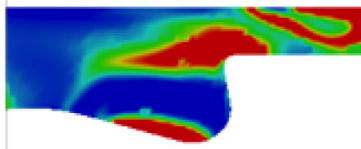

11.4 CAD aTDC

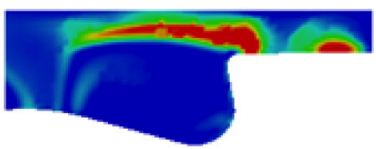

6.09 CAD aTDC

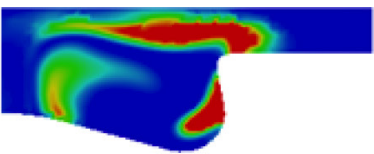

4.9 CAD aTDC

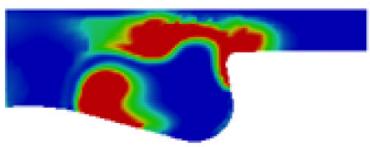

5.7 CAD aTDC

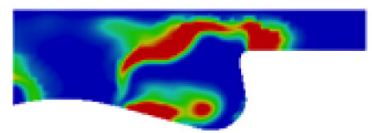

9.4 CAD aTDC

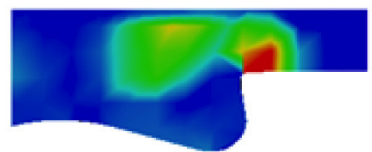

21.59 CAD aTDC

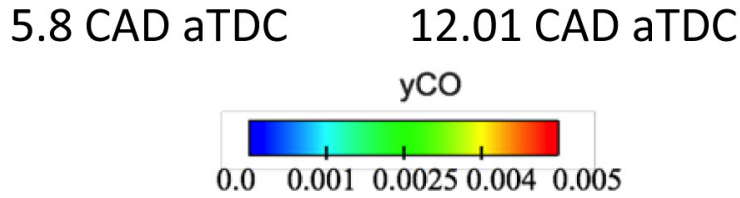

Figure 13. Y-Slice showing the in-cylinder CO formation at CA 10, CA 50 and CA 90 for various SOI's.

Soot emissions for the present operating conditions are expected to be minimal as no data point was observed in soot development regime. However, since diesel is well known for its emission characteristics, the sooting propensity is further discussed in terms of a precursor species, such as acetylene $\left(\mathrm{C}_{2} \mathrm{H}_{2}\right)$. Spatial examination of the concentration of $\mathrm{C} 2 \mathrm{H} 2$ at $\mathrm{CA} 10, \mathrm{CA} 50$ and $\mathrm{CA} 90$ in Figure 12 revealed that the amount of acetylene inside the cylinder is rather small. The in-cylinder location of acetylene formation is displayed in Figure 12. Later injection cases show more enhanced formation of acetylene. Combustion in the squish region at early injection cases can potentially lead to increased soot formation.
The late SOI's tends to produce higher $\mathrm{C}_{2} \mathrm{H}_{2}$ when compared with other SOI's. The total available mixing time between SOI to SOC determines the amount of acetylene formed during the entire combustion cycle.

Next the formation of $\mathrm{CO}$ is investigated. Figure 13 shows that the in-cylinder CO production is higher for early SOI's at CA10, CA50 and CA90, which reduces for later SOIs. CO formation is promoted in early injection case of -30 CAD owing to better in-cylinder mixing, which has also been reported in previous studies. As the SOI is retarded, the formation of CO is reduced and is mainly found in spray plume. Stronger formation of CO is revealed for early SOI cases. The very late injection case of -5 CAD shows an increase of 
$\mathrm{CO}$ and change in the trend due to the mixing time available between SOI and SOC. The mixture is well mixed when compared to other late injection cases. Overall, $\mathrm{CO}$ decreases as the mixing time increases. Later injection cases result in reduced CO formation when compared to early injection cases as shown in Figure 14.

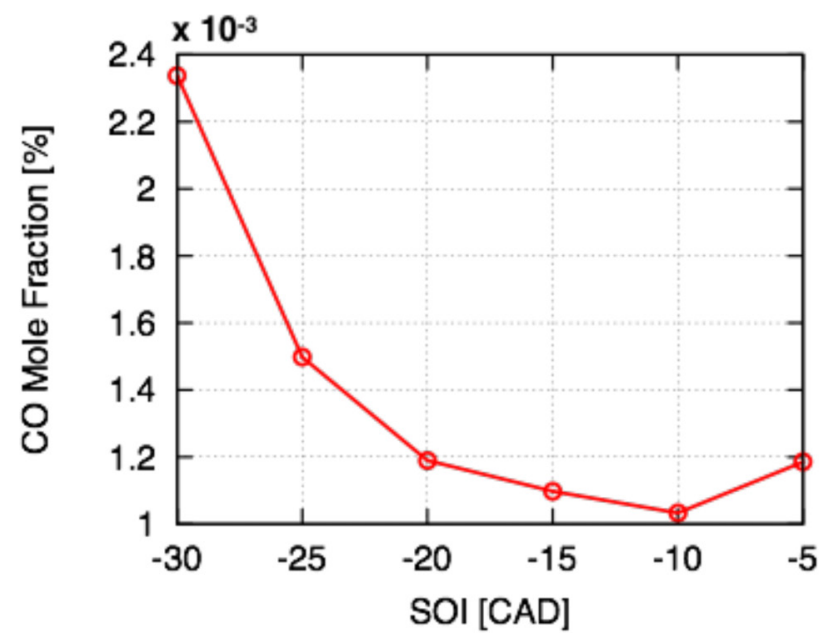

Figure 14. Total CO production during the entire combustion cycle

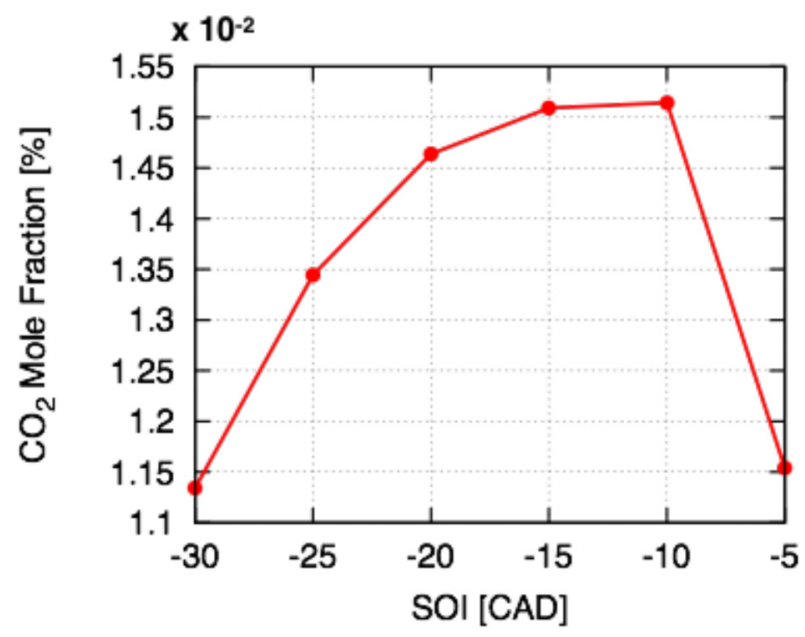

Figure 15. Total $\mathrm{CO} 2$ production during the entire combustion cycle.

Regarding $\mathrm{CO}_{2}$, its concentration first increases for later injection cases, but decreases for the very late injection case of -5 CAD. Increased pre-mixing turns the combustion lean to affect the combustion and resulted in less $\mathrm{CO}_{2}$ emissions, which can be seen from Figure 15. As the time available for mixing decreases, $\mathrm{CO}_{2}$ emission increases.

\section{Conclusions}

Simulation of the KAUST optical engine was performed using CONVERGETM and results of spray, combustion and emission behavior of diesel operating at CI and PPC were discussed in detail.

1. Different SOI was considered while the total amount of the injected fuel mass was fixed. Early SOI of -30 and -25 CAD resulted in fuel entering the squish region, whereas later SOI cases led to the entire amount of the injected fuel contained inside the piston bowl. Combustion in the squish region is undesirable due to lower temperature of the combustible air-fuel mixture reducing the combustion efficiency. PPC operation of the engine leads to mixing-controlled combustion of diesel. The in-cylinder equivalence ratio distribution varies from 0.6 to 1.5 , moving from lean to rich equivalence ratio as SOI is delayed.

2. The simulations yielded consistent behavior with experimental observations in that there exists a minimum CA50 throughout the SOI sweep from -30 to -5 CAD. Detailed investigation of temperature and mixture distribution indicated that SOI of -20 to -15 CAD resulted in the largest amount of the optimal mixture pockets at $0.9<\varphi<1.2$. SOI earlier than this condition resulted in too lean mixtures, while later SOI resulted in limited amount of mixture pockets that are too rich. The simulations clearly demonstrated that SOI and SOC are separated for PPC conditions, unlike conventional CI case.

3. Ignition location of the mixture was identified using scatter plot of T- $\varphi$ in reaction space. Early SOI of -30 CAD exhibited a very lean mixture and ignition location was found to be at a equivalence ratio range of 0.8 , also fuel in the squish region ignited first, followed by ignition in piston bowl. Intermediate SOI's resulted in $\varphi$ near stoichiometry and ignition was triggered near stoichiometry. Later injection cases resulted in mixing with richer pockets, which were able to trigger ignition and advance SOC, ignition location inside the cylinder was always triggered inside the bowl for the intermediate and later injection cases.

4. Scatter plot of T- $\varphi$ reaction phase when overlaid with soot-NOx regimes indicates that no data point was found at soot regime. High temperature and lean mixture conditions below $\varphi$ range of 1.5 indicate that many cells fell into the high temperature NOx regime. NOx production was found to increase for later SOIs due to higher flame temperature. Acetylene concentration was monitored as a key soot precursor species to further investigate the soot formation inside the cylinder. It was found that a considerable amount of acetylene was found at all SOIs, indicating that qualitative assessment using soot-NOx regime should not be used for low PPC engines. CO production was found to be higher for early injection case due to better mixing obtained due to the time available, whereas the later injection cases resulted in less $\mathrm{CO}$ formation.

Optical engine was simulated to understand the low level emissions from low compression ratio diesel engine. Detailed particulate soot model will be employed in future to better understand the soot formation process inside the diesel engine. Methods to improve the efficiency and reduce emission will be investigated with diesel and other drop-in fuels for diesel in CI mode.

\section{References}

1. Kokjohn, S., Hanson, R., Splitter, D., Kaddatz, J., "Fuel Reactivity Controlled Compression Ignition (RCCI) Combustion in Light- and Heavy-Duty Engines," SAE Int. J. Engines 4(1):360-374, 2011, doi:10.4271/2011-01-0357.

2. Heywood, J. B., "Internal combustion engine fundamentals". Mcgraw-hill New York: 1988; Vol. 930.

3. Tow, T., Pierpont, D., and Reitz, R., "Reducing Particulate and NOx Emissions by Using Multiple Injections in a Heavy Duty D.I. Diesel Engine," SAE Technical Paper 940897, 1994, doi:10.4271/940897. 
4. Maricq, M. M., "Chemical characterization of particulate emissions from diesel engines: A review". Journal of Aerosol Science, 38(11), 1079-1118, 2007.

5. Dec, J. E., "Advanced compression-ignition enginesunderstanding the in-cylinder processes". Proc. Comb inst 32(2), 2727-2742, 2009, doi:10.1016/j.proci.2008.08.008.

6. Hasegawa, R. and Yanagihara, H., "HCCI Combustion in DI Diesel Engine," SAE Technical Paper 2003-01-0745, 2003, doi:10.4271/2003-01-0745.

7. Alriksson, M. and Denbratt, I., "Low Temperature Combustion in a Heavy Duty Diesel Engine Using High Levels of EGR," SAE Technical Paper 2006-01-0075, 2006, doi:10.4271/2006-01-0075.

8. Cong, S. "An experimental study of low temperature combustion in a diesel engine". Shenghui Cong, 2011.

9. Yao, M.; Zheng, Z.; Liu, H., "Progress and recent trends in homogeneous charge compression ignition (HCCI) engines". Prog. Energy. Comb. Sci., 35(5), 398-437,2009, doi:10.1016/j. pecs.2009.05.001.

10. Christensen, M., Johansson, B., Amnéus, P., and Mauss, F., "Supercharged Homogeneous Charge Compression Ignition," SAE Technical Paper 980787, 1998, doi:10.4271/980787.

11. Noehre, C., Andersson, M., Johansson, B., and Hultqvist, A., "Characterization of Partially Premixed Combustion," SAE Technical Paper 2006-01-3412, 2006, doi:10.4271/2006-01-3412.

12. Manente, V., Zander, C., Johansson, B., Tunestal, P., "An Advanced Internal Combustion Engine Concept for Low Emissions and High Efficiency from Idle to Max Load Using Gasoline Partially Premixed Combustion," SAE Technical Paper 2010-01-2198, 2010, doi:10.4271/2010-01-2198.

13. Yanagihara, H.; Sato, Y.; Mizuta, J. In., "A simultaneous reduction of NOx and soot in diesel engines under a new combustion system (Uniform bulky combustion system UNIBUS), 17th International Vienna Motor Symposium, 303-314, 1996.

14. Kimura, S., Aoki, O., Kitahara, Y., and Aiyoshizawa, E., "UltraClean Combustion Technology Combining a Low-Temperature and Premixed Combustion Concept for Meeting Future Emission Standards," SAE Technical Paper 2001-01-0200, 2001, doi:10.4271/2001-01-0200.

15. Manente, V., Johansson, B., and Tunestal, P., "Partially Premixed Combustion at High Load using Gasoline and Ethanol, a Comparison with Diesel," SAE Technical Paper 2009-01-0944, 2009, doi:10.4271/2009-01-0944.

16. Manente, V., Johansson, B., Tunestal, P., and Cannella, W., "Effects of Different Type of Gasoline Fuels on Heavy Duty Partially Premixed Combustion," SAE Int. J. Engines 2(2):7188, 2010, doi:10.4271/2009-01-2668.

17. Manente, V., Tunestal, P., Johansson, B., and Cannella, W., "Effects of Ethanol and Different Type of Gasoline Fuels on Partially Premixed Combustion from Low to High Load," SAE Technical Paper 2010-01-0871, 2010, doi:10.4271/2010-01-0871.

18. Izadi Najafabadi, M., Dam, N., Somers, B., and Johansson, B., "Ignition Sensitivity Study of Partially Premixed Combustion by Using Shadowgraphy and $\mathrm{OH}^{*}$ Chemiluminescence Methods," SAE Technical Paper 2016-01-0761, 2016, doi:10.4271/2016-01-0761.
19. Yu, X., Zha, K., Luo, X., Taraza, D., "Simulation and Experimental Measurement of $\mathrm{CO}_{2}^{*}, \mathrm{OH}^{*}$ and $\mathrm{CH} 2 \mathrm{O}^{*}$ Chemiluminescence from an Optical Diesel Engine Fueled with n-Heptane," SAE Technical Paper 2013-24-0010, 2013, doi:10.4271/2013-24-0010.

20. Zha, K., Yu, X., Lai, M., and Jansons, M., "Investigation of Low-Temperature Combustion in an Optical Engine Fueled with Low Cetane Sasol JP-8 Fuel Using OH-PLIF and HCHO Chemiluminescence Imaging," SAE Technical Paper 2013-010898, 2013, doi: 10.4271/2013-01-0898.

21. Tanov, S., Collin, R., Johansson, B., and Tuner, M., "Combustion Stratification with Partially Premixed Combustion, PPC, using NVO and Split Injection in a LD - Diesel Engine," SAE Int. J. Engines 7(4):1911-1919, 2014, doi:10.4271/2014-01-2677.

22. Dempsey, A. B., Curran, S. J., Wagner, R. M., "A perspective on the range of gasoline compression ignition combustion strategies for high engine efficiency and low NOx and soot emissions: Effects of in-cylinder fuel stratification," Int. J Eng Res., 17(8), 897-917, 2016, doi:10.1177/1468087415621805.

23. Som, S., Aggarwal, S., "Effects of primary breakup modeling on spray and combustion characteristics of compression ignition engines," Combust Flame 157(2010): 1179-1193,2010, doi:10.1016/j.combustflame.2010.02.018.

24. Reitz, R. and Diwakar, R., "Effect of Drop Breakup on Fuel Sprays," SAE Technical Paper $\underline{860469}, 1986$, doi: $10.4271 / 860469$.

25. Reitz, R. and Diwakar, R., "Structure of High-Pressure Fuel Sprays," SAE Technical Paper $\underline{870598}$, 1987, doi:10.4271/870598.

26. Abramzon, B. Sirignano, W., "Droplet vaporization model for spray combustion calculations," Int. J heat mass transfer, 32(9), 1605-1618, 1989, doi:10.1016/0017-9310(89)90043-4

27. Han, Z. Reitz, R. D., "A temperature wall function formulation for variable-density turbulent flows with application to engine convective heat transfer modeling". Int. J of heat mass transfer 40(3), 613-625, 1997, doi:10.1016/0017-9310(96)00117-2.

28. Han, Z., Reitz, R. D., "Turbulence modeling of internal combustion engines using RNG $\kappa-\varepsilon$ models, Combust. sci. \& tech," 106(4-6), 267-295, 1995, doi: $10.1080 / 00102209508907782$.

29. Babajimopoulos, A., Assanis, D., Flowers, D., Aceves, S., Hessel R.P., "A fully coupled computational fluid dynamics and multi-zone model with detailed chemical kinetics for the simulation of premixed charge compression ignition engines," Int. J Eng Res. 6, (5)497-512, 2005 , doi: $10.1243 / 146808705 \times 30503$.

30. Richards, K., Senecal, P., Pomraning, E., "CONVERGE 2.2. 0 Theory Manual". Convergent Science Inc., Madison, WI (2013).

31. http://www.tfd.chalmers.se/ valeri/MECH.html

32. Hiroyasu, H. and Kadota, T., "Models for Combustion and Formation of Nitric Oxide and Soot in Direct Injection Diesel Engines," SAE Technical Paper 760129, 1976, doi: $10.4271 / 760129$. 
33. Kitamura, T., Ito, T., Senda, J., Fujimoto, H., "Mechanism of smokeless diesel combustion with oxygenated fuels based on the dependence of the equivalence ration and temperature on soot particle formation," Int. J Eng Res. 3, (4)223-248, 2002, doi:10.1243/146808702762230923.

\section{Contact information}

Mr. Mohammed Jaasim Mubarak Ali

$\mathrm{PhD}$ student

Clean Combustion Research Centre (CCRC)

King Abdullah University of Science and Technology (KAUST)

Thuwal, Saudi Arabia

mohammedjaasim.mubarakali@,kaust.edu.sa

Phone no - +966569060 779

\section{Acknowledgments}

This work was funded by competitive research funding from King Abdullah University of Science and Technology (KAUST) under the Clean Combustion Research Center's research program. We also acknowledge funding from Saudi Aramco under the FUELCOM program. Finally, we would like to express our gratitude to our research Technician, Adrian I. Ichim for his support in carrying out the experiments at KAUST engine lab.

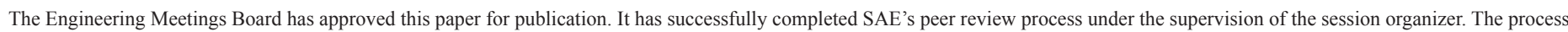
requires a minimum of three (3) reviews by industry experts.

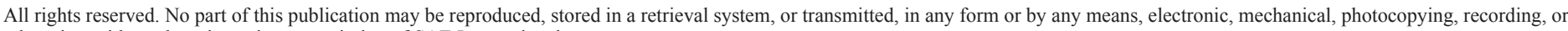
otherwise, without the prior written permission of SAE International.

Positions and opinions advanced in this paper are those of the author(s) and not necessarily those of SAE International. The author is solely responsible for the content of the paper.

ISSN 0148-7191

http://papers.sae.org/2017-01-0573 